\title{
Leucoplasia pilosa oral: aspectos histopatológicos da fase subclínica
}

\section{Oral hairy leukoplakia: histopathologic features of the subclinical stage}

\author{
Eliane Pedra DIAS* \\ Kyria Spyro SPYRIDES** \\ Arley SILVA JUNIOR** \\ Mônica Lage ROCHA** \\ Eliene Carvalho da FONSECA***
}

\begin{abstract}
DIAS, E. P.; SPYRIDES, K. S.; SILVA JUNIOR, A.; ROCHA, M. L.; FONSECA, E. C. da. Leucoplasia pilosa oral: aspectos histopatológicos da fase subclínica. Pesqui Odontol Bras, v. 15, n. 2, p. 104-111, abr./jun. 2001.
\end{abstract}

\begin{abstract}
A leucoplasia pilosa oral (LPO) é uma das manifestações orais mais comuns na AIDS, com valor diagnóstico e prognóstico. A LPO está relacionada ao Epstein-Barr vírus (EBV), com características clínicas e histopatológicas definidas. Já existem relatos de uma fase subclínica da LPO, porém sem caracterização histopatológica. O presente trabalho teve por objetivo descrever os aspectos histopatológicos desta fase, bem como realizar uma análise comparativa entre a LPO subclínica e clínica, com a finalidade de verificar a suficiência diagnóstica dos critérios histopatológicos. Trata-se de um estudo retrospectivo de 11 casos, obtidos a partir de cinco biópsias realizadas em pacientes com lesão e da borda de seis línguas sem lesão macroscopicamente detectável, provenientes de necropsias. Foram utilizados os seguintes métodos: histopatologia, imuno-histoquímica e hibridização in situ. Os aspectos histopatológicos que caracterizaram a fase subclínica da LPO foram: ausência de paraceratose e papilomatose, acantose leve, presença de células claras e alterações nucleares (inclusão tipo Cowdry A, núcleo em "vidro fosco" e núcleo "em colar"). Houve identificação do EBV através da hibridização in situ e da imuno-histoquímica nas alterações nucleares observadas na histopatologia. Concluiu-se, com fundamentos na identificação do EBV nas alterações nucleares, que a LPO em sua fase subclínica, da mesma forma que na lesão clínica, apresenta características histopatológicas específicas e suficientes para um diagnóstico definitivo, independentemente da identificação do EBV.
\end{abstract}

UNITERMOS: Leucoplasia pilosa; Herpesvirus 4 humano.

\section{INTRODUÇÃO}

A leucoplasia pilosa é a única lesão oral nova, reconhecida a partir da epidemia da AIDS. Foi descrita pela primeira vez por GREENSPAN et al. ${ }^{13}$, em 1984, que verificaram a sua ocorrência em homossexuais masculinos, soropositivos para o HIV. A leucoplasia pilosa oral (LPO) manifesta-se clinicamente como uma placa branca, caracteristicamente não removivel através de raspagem, com localização preferencial nas bordas laterais da língua, podendo ser uni- ou bilateral. A superficie pode apresentar-se plana, corrugada ou pilosa, sendo seus aspectos clínicos característicos, porém não patognomônicos ${ }^{7,13,14}$.

Os pacientes soropositivos para o HIV consti- tuem o grupo de predileção, sendo rara em crianças e adolescentes ${ }^{20,21}$. Geralmente é observada em imunossuprimidos, porém existem alguns relatos em pacientes sem qualquer alteração imunológi$\mathrm{ca}^{4,6,8}$. A partir de 1987, através de várias metodologias, a etiologia da LPO foi associada à presença do $\mathrm{EBV}^{9,14,17}$. Trata-se de uma infecção permissiva, em que o EBV pode estar presente na saliva ou em células adjacentes infectadas ${ }^{27,29}$.

O aspecto histopatológico é caracterizado por hiperceratose, paraceratose, acantose, papilomatose, presença de células balonizadas com alterações nucleares na camada espinhosa, discreto infiltrado inflamatório intra-epitelial e no tecido conjuntivo subjacente que, freqüentemente, está

* Doutora em Patologia; **Mestres em Patologia Buco-Dental; ***Mestra em Imunologia- Departamento de Patologia da Universidade Federal Fluminense. 
DIAS, E. P.; SPYRIDES, K. S.; SILVA JUNIOR, A.; ROCHA, M. L.; FONSECA, E. C. da. Leucoplasia pilosa oral: aspectos histopatológicos da fase subclínica. Pesqui Odontol Bras, v. 15, n. 2, p. 104-111, abr./jun. 2001.

associado à presença de candidíase $\mathrm{e}^{5,10,11,12,16,31}$. A1guns autores descrevem as alterações nucleares associadas ao EBV como um critério suficiente para o diagnóstico histopatológico e que, se estes forem representativos, os demais métodos não seriam necessários para o diagnóstico ${ }^{3,10,11,25}$. Outros autores porém, consideram necessária a identificação do DNA do EBV, particularmente após a descrição da pseudoleucoplasia pilosa (lesão branca com aspecto histopatológico semelhante a LPO e com hibridização in situ negativa para o EBV) e da identificação de casos falso-positivos e falso-negativos $^{5,12,15}$.

A importância da LPO no diagnóstico e prognóstico da AIDS justifica a necessidade da precocidade e precisão diagnóstica, sendo que alguns estudos já apontam a citopatologia como método diagnóstico de escolha ${ }^{2,3,5,11,14,19,25,32}$.

A literatura relata a LPO como uma lesão clinicamente detectável, porém já existem alguns relatos de uma fase subclínica identificável pela presença do $\mathrm{EBV}^{1,22,24,26,30}$. Nos estudos referentes à infecção subclínica, esta fase não foi bem caracterizada sob o ponto de vista histopatológico ${ }^{23}$. ROCHA et $a .^{28}$ (1999), estudaram a borda da lingua em 100 necropsias e identificaram em cinco casos, a partir da análise histopatológica, a presença das alterações nucleares da LPO descritas por FRAGA-FERNÁNDEZ et al. ${ }^{10}$ (1990). Em nenhum dos casos havia alteração detectável ao exame macroscópico da língua, sendo a imuno-histoquímica positiva para o EBV. Dessa forma, concluiram que a LPO ainda numa fase subclínica é identificável através da histopatologia, embora, os aspectos histopatológicos não tenham sido suficientemente detalhados.

Nosso objetivo foi o de verificar a suficiência diagnóstica da histopatologia; a identificação imuno-histoquímica e molecular do EBV, bem como caracterizar morfologicamente a fase subclinica da LPO; comparar os aspectos histopatológicos das fases clínica e subclínica; avaliar quantitativamente as alterações nucleares e investigar a constituição molecular das alterações nucleares correspondentes ao efeito citopático do EBV.

\section{MATERIAL E MÉTODOS Seleção da amostra}

Este foi um estudo retrospectivo de 11 casos de LPO, dos quais cinco representaram a LPO clínica e seis corresponderam à caracterização da fase subclinica.
Identificaram-se, no setor de cabeça e pescoço do Serviço de Anatomia Patológica do Hospital Universitário Antônio Pedro (SAP/HUAP), 15 casos diagnosticados como LPO. A partir da análise dos dados clínicos existentes nos arquivos e das respectivas lâminas e blocos de parafina, foram selecionados cinco casos de LPO clínica de acordo com os seguintes critérios: quantidade de material remanescente no bloco de parafina; inclusão adequada da biópsia; lesão bem representada no corte histopatológico, com aspectos característicos referidos na literatura e casos representativos das três formas clínicas: plana, corrugada e pilosa ${ }^{10,32}$. Os cinco pacientes, que sofreram as biópsias, apresentavam manifestações decorrentes da AIDS, com idade variando de 30 a 56 anos, sendo quatro do sexo masculino e homossexuais. Em relação a outras manifestações bucais, dois pacientes apresentavam candidíase.

Os casos de LPO subclínica foram obtidos a partir de um estudo anterior em que foram avaliadas bordas de lingua sem lesão macroscopicamente detectável, provenientes de necropsias do Serviço de Anatomia Patológica do Hospital Universitário Antônio Pedro (SAP/HUAP) ${ }^{28}$. Em quatro casos, o óbito foi decorrente de complicações ocasionadas pela AIDS, em um decorrente de adenocarcinoma de pulmão e no último de trombo-embolismo pulmonar; sendo todas as pacientes do sexo feminino, com idade variando entre 19 e 82 anos. A identificação dos casos de LPO subclínica foi obtida pela avaliação histopatológica.

\section{Avaliação histopatológica e identificação do EBV}

Os blocos parafinados dos 11 casos selecionados foram encaminhados para microtomia, onde realizaram-se cortes de $4 \mu \mathrm{m}$ de espessura. Foram confeccionadas quatro lâminas de cada bloco coradas por: hematoxilina-eosina $(\mathrm{HE})$, tricrômio de Gomori, ácido periódico de Schiff (PAS) e coloração de Feulgen.

As lâminas coradas por $\mathrm{HE}$ foram examinadas ao microscópio óptico, sendo avaliada a presença de: hiperceratose, paraceratose, acantose, hiperplasia da camada basal, papilomatose, células claras, alterações nucleares nos ceratinócitos (inclusão tipo Cowdry A, núcleo em "vidro fosco" e núcleo "em colar"), candidíase, depósito de glicogênio, exocitose e infiltrado inflamatório no córion. $\mathrm{O}$ tricrômio de Gomori foi utilizado para avaliação da presença de ceratina e o PAS para identificação de 
DIAS, E. P.; SPYRIDES, K. S.; SILVA JUNIOR, A.; ROCHA, M. L.; FONSECA, E. C. da. Leucoplasia pilosa oral: aspectos histopatológicos da fase subclínica. Pesqui Odontol Bras, v. 15, n. 2, p. 104-111, abr./jun. 2001.

candidiase. O método histoquímico de Feulgen para identificação de DNA foi utilizado para investigar a constituição molecular das alterações nucleares (controle positivo: núcleos de ceratinócitos normais).

A espessura epitelial foi mensurada em centímetros, em fotomicrografias das lesões, utilizando-se objetiva e ocular de 10 aumentos.

Realizou-se uma análise semiquantitativa das alterações nucleares nos ceratinócitos através de contagem em dez campos microscópicos de $40 \mathrm{X}$. Os valores obtidos foram somados e os resultados expressos em valor percentual.

Todos os casos foram submetidos a imuno-histoquímica e hibridização in situ em cortes obtidos dos blocos de parafina provenientes das bordas laterais das linguas estudadas. Na imuno-histoquímica, utilizou-se o anticorpo monoclonal anti-EBV (EBV "latent membrane protein mouse monoclonal antibody" - NCL-EBV-PE2 NOVOCASTRA), conforme descrito por KANAS et al. ${ }^{17}$ (1988). A hibridização in situ foi realizada com a sonda de DNA para identificação do EBV (Enzo Diagnostic Inc., New York, NY) segundo orientação do fabricante. Essa técnica foi realizada com a sonda EBV-DNA biotinilada, enzimaticamente detectada com complexo avitina-biotina, e finalmente revelada pela adição de aminoetilcarbazole. Como controle positivo, utilizou-se um caso de LPO com diagnóstico confirmado pelas mesmas técnicas de imuno-histoquímica e hibridização in situ. Como controle negativo utilizaram-se áreas, nos próprios cortes, sem adição do anticorpo anti-EBV ou sonda de DNA.

\section{RESULTADOS Leucoplasia pilosa oral}

A LPO foi identificada nas bordas laterais da lingua de todos os pacientes. Em um caso apresentava tamanho pequeno, em dois médio e nos outros dois grande. Em relação à configuração, duas apresentavam aspecto plano, duas corrugado e uma pilosa. A maioria das lesões foi encontrada em exames odontológicos de rotina e somente as lesões grandes constituíram a queixa principal do paciente.

Todos os aspectos histopatológicos investigados foram identificados (Figura 1A) e encontramse listados na Tabela 1. A avaliação da espessura do epitélio variou de 8,0 a $17,5 \mathrm{~cm}$, sendo identificada uma correlação direta entre a intensidade de hiperceratose e acantose, espessura epitelial e configuração clínica da LPO (Tabelas 1,2).

As alterações nucleares tipo Cowdry A foram encontradas nas camadas intermediária e superficial do epitélio, sobretudo nas células claras. O núcleo em "vidro fosco" foi encontrado nas camadas intermediária, superficial e de paraceratose, predominando na camada superficial. O núcleo "em colar" foi encontrado predominantemente nas camadas superficial e de paraceratose. Na análise semiquantitativa (Gráfico 1), a alteração nuclear mais freqüente foi o "vidro fosco", com um total variável de 33 a 69 núcleos por caso; depois o núcleo "em colar" (1 a 42 núcleos por caso) e por último o Cowdry A (4 a 30 núcleos por caso).
FIGURA 1 - A: leucoplasia pilosa oral clínica (caso 1) (H.E., 100 X) B: leucoplasia pilosa oral subclínica (caso 3 ) (H.E., $100 \mathrm{X})$.
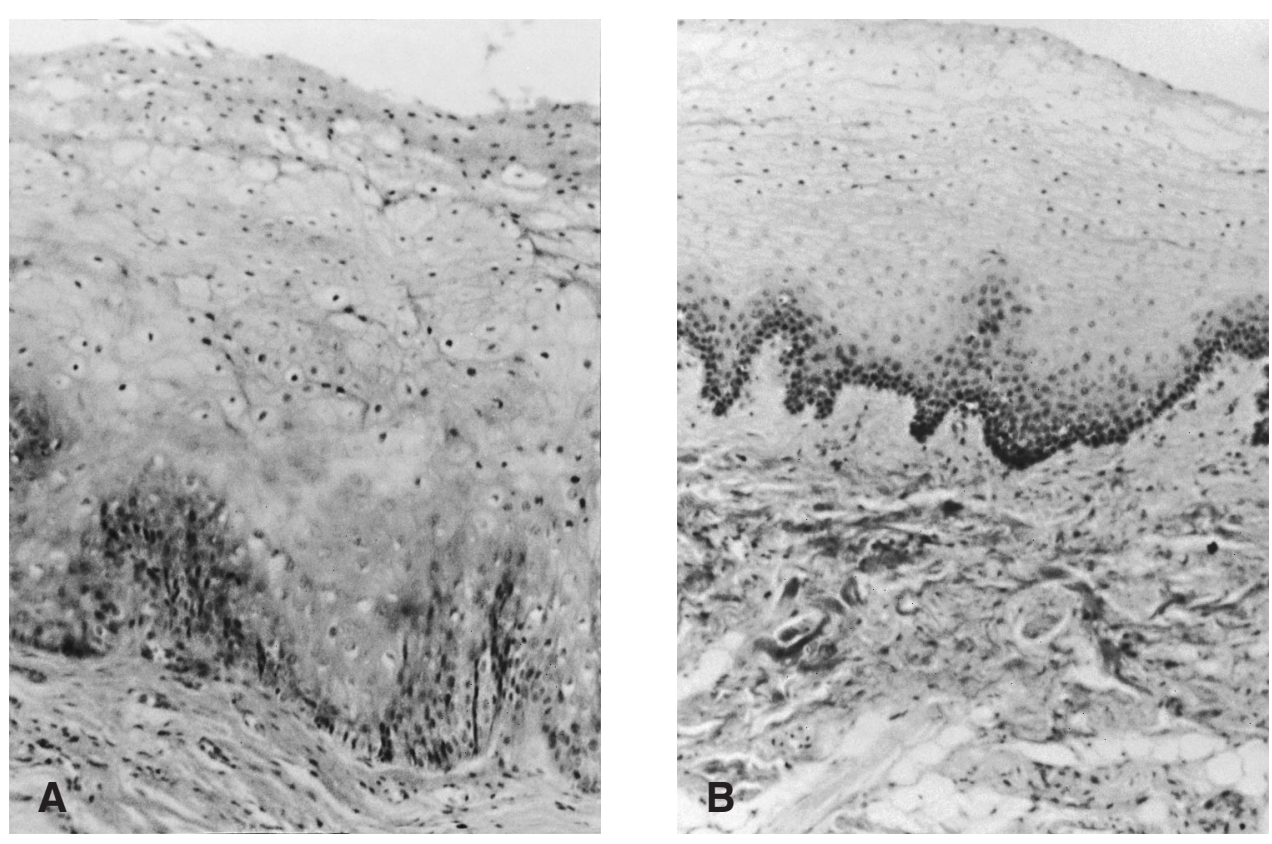
DIAS, E. P.; SPYRIDES, K. S.; SILVA JUNIOR, A.; ROCHA, M. L.; FONSECA, E. C. da. Leucoplasia pilosa oral: aspectos histopatológicos da fase subclínica. Pesqui Odontol Bras, v. 15, n. 2, p. 104-111, abr./jun. 2001.

TABELA 1 - Aspectos histopatológicos da leucoplasia pilosa oral clinicamente detectável e correlação com a configuração da lesão.

\begin{tabular}{|c|c|c|c|c|c|}
\hline $\mathrm{A} \mathrm{Hp}^{\mathrm{N}^{\mathrm{o}}}$ & 1 & 2 & 3 & 4 & 5 \\
\hline Hiperceratose & $\mathrm{L}$ & $\mathrm{M}$ & $\mathrm{L}$ & $\mathrm{L}$ & A \\
\hline Paraceratose & $\mathrm{D}$ & $\mathrm{D}$ & $\mathrm{D}$ & $\mathrm{D}$ & $\mathrm{D}$ \\
\hline Acantose & $\mathrm{M}$ & $\mathrm{M}$ & $\mathrm{M}$ & $\mathrm{M}$ & A \\
\hline $\begin{array}{l}\text { Hiperplasia } \\
\text { da basal }\end{array}$ & $\mathrm{Au}$ & $\mathrm{P}$ & $\mathrm{P}$ & $\mathrm{P}$ & $\mathrm{Au}$ \\
\hline Papilomatose & $\mathrm{P}$ & $\mathrm{P}$ & $\mathrm{P}$ & $\mathrm{P}$ & $\mathrm{P}$ \\
\hline Células claras & $\mathrm{D}$ & $\mathrm{D}$ & $\mathrm{D}$ & $\mathrm{F}$ & $\mathrm{D}$ \\
\hline $\begin{array}{l}\text { Alterações } \\
\text { nucleares }\end{array}$ & $\mathrm{P}$ & $\mathrm{P}$ & $\mathrm{P}$ & $\mathrm{P}$ & $\mathrm{P}$ \\
\hline Candidíase & $\mathrm{Au}$ & $\mathrm{Au}$ & $\mathrm{Au}$ & $\mathrm{P}$ & $\mathrm{P}$ \\
\hline $\begin{array}{l}\text { Depósito de } \\
\text { glicogênio }\end{array}$ & D & D & $\mathrm{D}$ & $\mathrm{D}$ & $\mathrm{D}$ \\
\hline Exocitose & $\mathrm{Au}$ & $\mathrm{Au}$ & $\mathrm{P}$ & $\mathrm{P}$ & $\mathrm{P}$ \\
\hline $\begin{array}{l}\text { Infiltrado } \\
\text { inflamatório }\end{array}$ & $\mathrm{Au}$ & $\mathrm{Au}$ & $\mathrm{P}$ & $\mathrm{P}$ & $\mathrm{P}$ \\
\hline $\begin{array}{l}\text { Configuração } \\
\text { da lesão }\end{array}$ & Plana & Plana & Corrugada & Corrugada & Pilosa \\
\hline
\end{tabular}

$\mathrm{N}^{\circ}=$ número do caso; $\mathrm{A} \mathrm{Hp}=$ aspecto histopatológico; $\mathrm{L}=$ leve $; \mathrm{M}=$ moderado; $\mathrm{A}=$ acentuado $; \mathrm{F}=$ focal; $\mathrm{D}=$ difuso; $\mathrm{Au}=$ ausente $\mathrm{P}=$ presente.

As técnicas de imuno-histoquímica e hibridização in situ revelaram, em todos os casos, positividade nuclear em intensidades variadas, identificada nas inclusões tipo Cowdry A e "vidro fosco". Não observamos imunopositividade no núcleo "em colar" e, na hibridização in situ, alguns exibiram fraca marcação central.

\section{Leucoplasia pilosa oral subclínica}

A fase subclinica da LPO (Figura 1B) caracterizou-se por ausência de hiperceratose; papilomatose ausente ou discreta; paraceratose ausente ou focal; acantose leve e correspondente a espessura epitelial; células claras; hiperplasia da camada basal e alterações nucleares, facilmente observadas. A candidiase foi diagnosticada em três casos e o infiltrado inflamatório, quando presente, foi discreto (Tabela 3).

A avaliação da distribuição das alterações nucleares pelas diferentes camadas epiteliais demonstrou que as inclusões tipo Cowdry A foram as mais freqüentes, com um total variável de 32 a 116 núcleos por caso e observadas nas camadas
TABELA 2 - Avaliação da espessura do epitélio na leucoplasia pilosa oral e correlação com a configuração clínica.

\begin{tabular}{c|c|c|c|c}
\hline \hline $\mathrm{N}^{\mathrm{o}}$ & Hiperceratose & Acantose & $\begin{array}{c}\text { Espessura } \\
\text { (avaliação } \\
\text { quantitativa) }\end{array}$ & $\begin{array}{c}\text { Configuração } \\
\text { clínica }\end{array}$ \\
\hline 1 & $1,0 \mathrm{~cm}$ & $7,0 \mathrm{~cm}$ & $8,0 \mathrm{~cm}$ & Plana \\
\hline 2 & $1,5 \mathrm{~cm}$ & $7,5 \mathrm{~cm}$ & $9,0 \mathrm{~cm}$ & Plana \\
\hline 3 & $1,0 \mathrm{~cm}$ & $9,5 \mathrm{~cm}$ & $10,5 \mathrm{~cm}$ & Corrugada \\
\hline 4 & $1,0 \mathrm{~cm}$ & $9,0 \mathrm{~cm}$ & $10,0 \mathrm{~cm}$ & Corrugada \\
\hline 5 & $2,5 \mathrm{~cm}$ & $15,0 \mathrm{~cm}$ & $17,5 \mathrm{~cm}$ & Pilosa \\
\hline \hline
\end{tabular}

$\mathrm{N}^{\circ}=$ número do caso.

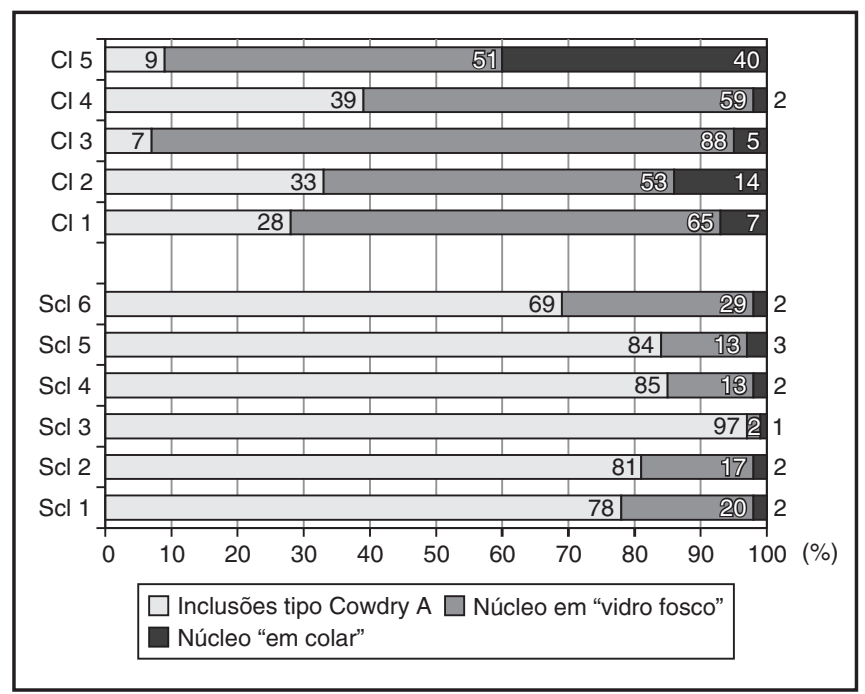

GRÁFICO 1 - Variação quantitativa das alterações nucleares na leucoplasia pilosa oral subclínica (Scl) e clínica $(\mathrm{Cl})$.

intermediária e superficial. Os núcleos em "vidro fosco" (2 a 49 núcleos por caso) predominaram nas camadas superficial e intermediária e os núcleos "em colar" foram ocasionais (1 a 4 núcleos por caso) e restritos aos esparsos focos de ceratinização e/ou na camada superficial (Gráfico 1).

Todos os casos apresentaram imunopositividade para o EBV, em localização nuclear, predominantemente nas inclusões Cowdry $\mathrm{A}$, repetindo o mesmo padrão identificado nas lesões clínicas (Figuras $2 \mathrm{Ae} 3 \mathrm{~A}$ ). A hibridização in situ revelou vários núcleos marcados em azul, nas camadas superficial e intermediária do epitélio, especificamente nas inclusões tipo Cowdry A e nos núcleos em "vidro fosco"; já nos núcleos "em colar" a marcação, quando presente, apresentou-se fraca e central (Figuras 2B e 3B) . 
DIAS, E. P.; SPYRIDES, K. S.; SILVA JUNIOR, A.; ROCHA, M. L.; FONSECA, E. C. da. Leucoplasia pilosa oral: aspectos histopatológicos da fase subclínica. Pesqui Odontol Bras, v. 15, n. 2, p. 104-111, abr./jun. 2001.

TABELA 3 - Aspectos histopatológicos e avaliação da espessura epitelial da fase subclínica da leucoplasia pilosa oral.

\begin{tabular}{|c|c|c|c|c|c|c|}
\hline $\mathrm{A} \mathrm{Hp}^{\mathrm{N}^{\mathrm{o}}}$ & 1 & 2 & 3 & 4 & 5 & 6 \\
\hline Hiperceratose & $\mathrm{Au}$ & $\mathrm{Au}$ & $\mathrm{Au}$ & $\mathrm{Au}$ & $\mathrm{Au}$ & $\mathrm{Au}$ \\
\hline Paraceratose & $\mathrm{F}$ & $\mathrm{F}$ & $\mathrm{Au}$ & $\mathrm{Au}$ & $\mathrm{Au}$ & $\mathrm{F}$ \\
\hline $\begin{array}{l}\text { Acantose e } \\
\text { espessura } \\
\text { epitelial }\end{array}$ & $\begin{array}{c}\mathrm{L} \\
6,5 \mathrm{~cm}\end{array}$ & $\begin{array}{c}\mathrm{L} \\
4,0 \mathrm{~cm}\end{array}$ & $\begin{array}{c}\mathrm{L} \\
5,5 \mathrm{~cm}\end{array}$ & $\begin{array}{c}\mathrm{L} \\
5,0 \mathrm{~cm}\end{array}$ & $\begin{array}{c}\mathrm{L} \\
2,5 \mathrm{~cm}\end{array}$ & $\begin{array}{c}\mathrm{L} \\
6,0 \mathrm{~cm}\end{array}$ \\
\hline $\begin{array}{l}\text { Hiperplasia } \\
\text { da basal }\end{array}$ & $\mathrm{P}$ & $\mathrm{P}$ & $\mathrm{Au}$ & $\mathrm{P}$ & $\mathrm{P}$ & $\mathrm{P}$ \\
\hline Papilomatose & $\mathrm{P}$ & $\mathrm{Au}$ & $\mathrm{Au}$ & $\mathrm{Au}$ & $\mathrm{Au}$ & $\mathrm{P}$ \\
\hline Células claras & $\mathrm{D}$ & $\mathrm{D}$ & $\mathrm{D}$ & $\mathrm{D}$ & $\mathrm{D}$ & $\mathrm{D}$ \\
\hline $\begin{array}{l}\text { Alterações } \\
\text { nucleares }\end{array}$ & $\mathrm{P}$ & $\mathrm{P}$ & $\mathrm{P}$ & $\mathrm{P}$ & $\mathrm{P}$ & $\mathrm{P}$ \\
\hline Candidíase & $\mathrm{P}$ & $\mathrm{P}$ & $\mathrm{P}$ & $\mathrm{Au}$ & $\mathrm{Au}$ & $\mathrm{Au}$ \\
\hline $\begin{array}{l}\text { Depósito de } \\
\text { glicogênio }\end{array}$ & D & $\mathrm{D}$ & D & $\mathrm{D}$ & $\mathrm{D}$ & $\mathrm{D}$ \\
\hline Exocitose & $\mathrm{Au}$ & $\mathrm{P}$ & $\mathrm{Au}$ & $\mathrm{P}$ & $\mathrm{Au}$ & $\mathrm{Au}$ \\
\hline $\begin{array}{l}\text { Infiltrado in- } \\
\text { flamatório }\end{array}$ & $\mathrm{Au}$ & $\mathrm{Au}$ & $\mathrm{Au}$ & $\mathrm{P}$ & $\mathrm{Au}$ & $\mathrm{P}$ \\
\hline
\end{tabular}

$\mathrm{N}^{\circ}=$ número do caso; $\mathrm{A} \mathrm{Hp}=$ aspecto histopatológico; $\mathrm{Au}=$ ausente $\mathrm{P}=$ presente $\mathrm{L}=$ leve $; \mathrm{F}=$ focal $; \mathrm{D}=$ difuso.

\section{Análise comparativa entre a LPO subclínica e clínica}

A LPO clínica caracterizou-se pela presença de hiperceratose, paraceratose, acantose e papilomatose. A hiperceratose esteve ausente na fase subclínica e os demais aspectos foram pouco expressivos, sendo compativel com a ausência de expressão clínica (Figura 1). As características alterações nucleares apresentaram uma notável variação quantitativa, com o predomínio do núcleo em "vidro fosco" na LPO clínica e do Cowdry A na LPO subclínica. O núcleo "em colar", freqüentemente encontrado na LPO clínica, foi raramente identificado na LPO subclínica (Gráfico 1).

\section{Constituição molecular das alterações nucleares}

Nos ceratinócitos com as alterações nucleares representativas do efeito citopático do EBV, a reação de Feulgen foi positiva tanto nas inclusões tipo Cowdry A e "vidro fosco", quanto nos núcleos "em colar", diferindo da positividade pela imuno-histo- química e hibridização in situ, sempre ausente nos núcleos "em colar". Dessa forma, verificou-se que as alterações nucleares tipo Cowdry A e "vidro fosco" correspondem ao DNA do EBV, já os fragmentos esféricos e marginais, tão característicos do núcleo "em colar", correspondem à fragmentação da cromatina humana.

\section{DISCUSSÃO}

As primeiras descrições histopatológicas da LPO não relataram alterações nucleares nos ceratinócitos infectados pelo $\mathrm{EBV}^{7,12,13,17}$. Apesar de estudos posteriores considerarem as alterações nucleares representativas do efeito citopático do EBV, alguns autores permanecem creditando o diagnóstico da LPO apenas à identificação do DNA-EBV ${ }^{10,16,19}$. Em 1998, GREENSPAN et al. ${ }^{15}$ (1998) realizaram uma análise comparativa entre os achados histopatológicos e por hibridização in situ em 60 pacientes com lesões suspeitas de LPO e concluíram que, em decorrência da possibilidade de falso-positivos e negativos, a histopatologia não deve substituir a hibridização in situ no diagnóstico definitivo da LPO. Apesar da ampla casuística, GREENSPAN et al. ${ }^{15}$ (1998) não descreveram detalhadamente os critérios histopatológicos. Em nosso estudo, obtivemos $100 \%$ de correlação entre a histopatologia e a imuno-histoquímica/hibridização in situ. Esses resultados indicam que a histopatologia é suficiente para o diagnóstico de LPO, desde que se observem rigorosamente os critérios diagnósticos, isto é: presença inquestionável das três alterações nucleares representativas do efeito citopático do EBV e que a hibridização in situ possa ser reservada para os casos duvidosos, onde as alterações nucleares não se expressem da forma característica ou estejam ausentes (pseudoleucoplasia pilosa).

Alguns estudos identificaram o EBV no epitélio de mucosa oral clinicamente normal, em pacientes imunossuprimidos ${ }^{1,23,24,30}$. Entretanto, nenhum desses relatou a possibilidade do EBV produzir alterações histopatológicas prévias à expressão clínica. Nossos resultados demonstraram que a histopatologia é um método suficientemente sensível e específico também para diagnosticar a LPO numa fase incipiente ou subclínica. Além disso, identificaram diferenças quantitativas que permitiram uma correlação entre o aspecto clínico e histopatológico em ambas as fases.

Muitos estudos utilizaram técnicas moleculares 
DIAS, E. P.; SPYRIDES, K. S.; SILVA JUNIOR, A.; ROCHA, M. L.; FONSECA, E. C. da. Leucoplasia pilosa oral: aspectos histopatológicos da fase subclínica. Pesqui Odontol Bras, v. 15, n. 2, p. 104-111, abr./jun. 2001.

para identificação do DNA do EBV $\mathrm{E}^{9,10,22,24,25}$. Da mesma forma, verificamos a correspondência entre as inclusões nucleares Cowdry A/"vidro fosco" e positividade para o DNA-EBV, de modo que parece não haver dúvidas em relação à constituição molecular dessas inclusões. Já o núcleo "em colar", Feulgen positivo e EBV negativo, é constituído por fragmentos esféricos de cromatina humana e possivelmente corresponde a um tipo particular de cariorrexe. A variação quantitativa das alterações nucleares reflete a dinâmica morfológica da LPO.
Pela importância diagnóstica e prognóstica da LPO, acreditamos que a detecção da fase subclínica possa contribuir no diagnóstico e acompanhamento da AIDS, bem como de outros estados imunossupressores. Entretanto, a ausência de lesão clínica representa um impeditivo à biópsia. Por outro lado, a citopatologia é um método simples, seguro, não invasivo e de baixo custo ${ }^{3,5,11,24,31}$. Considerando-se que a sua utilização nas lesões clínicas já é reconhecida, é possivel que este exame possa fornecer o diagnóstico também da fase subclínica.

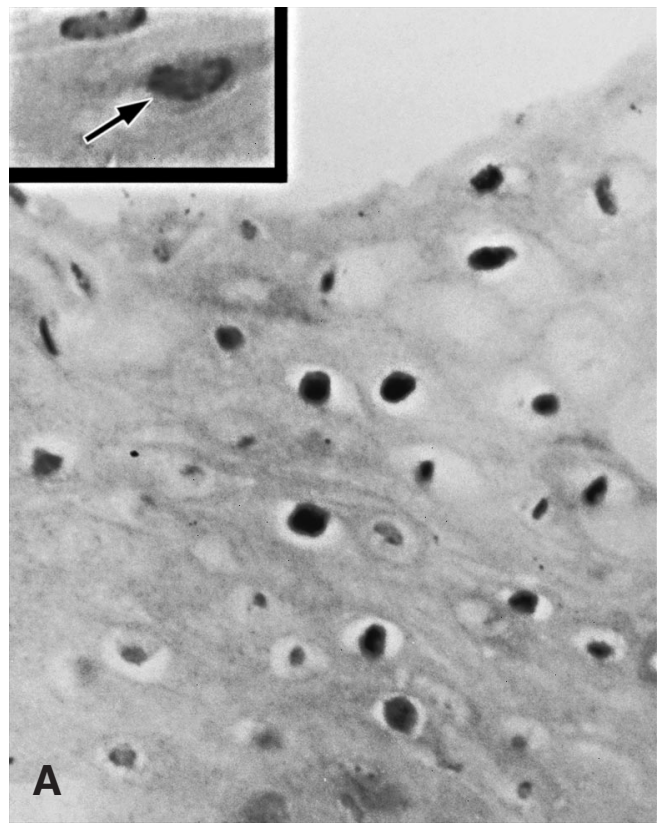

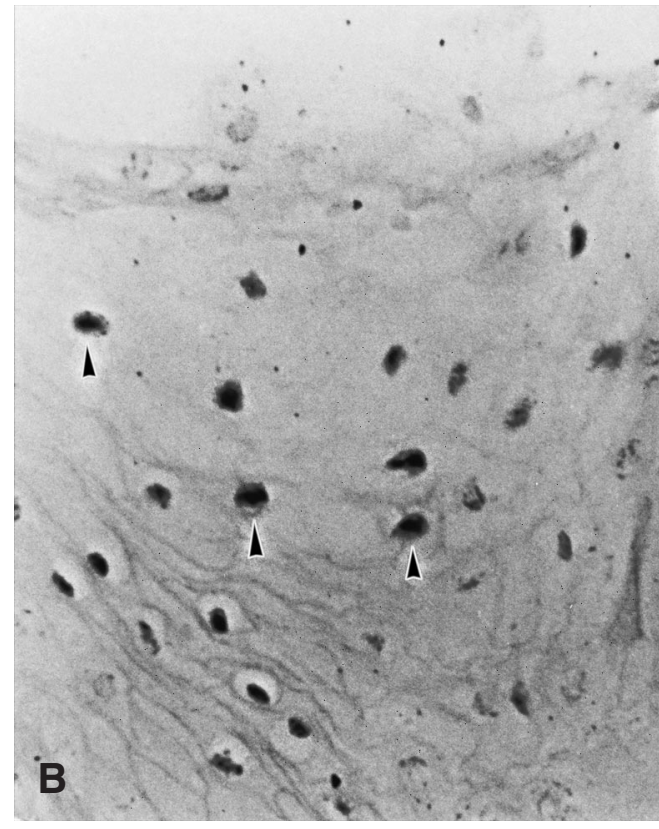

FIGURA 2 -

Identificação do vírus Epstein-Barr na leucoplasia pilosa subclínica (caso 1). A: imuno-histoquímica células claras com núcleos corados (400 X) -; detalhe núcleo "em colar" imunonegativo (1.000 X). B: hibridização in situ células claras com núcleos corados (400 X).

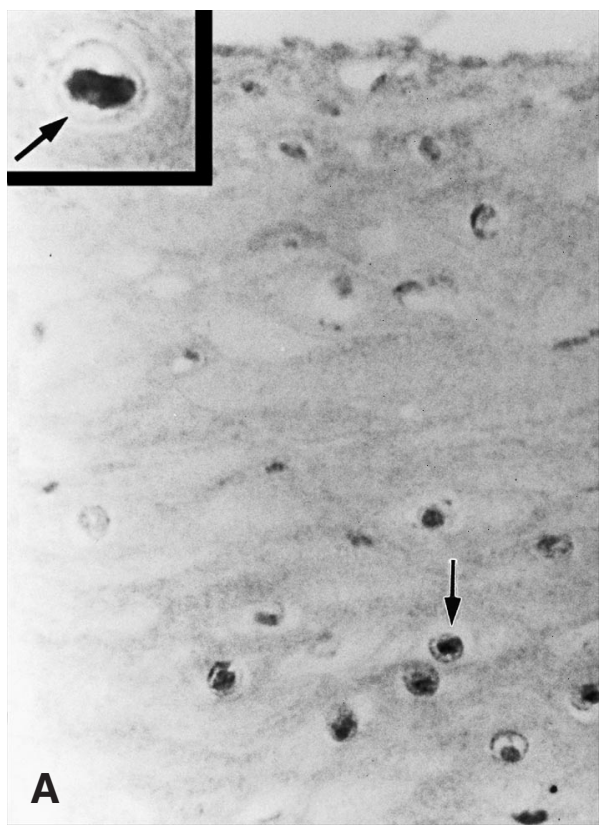

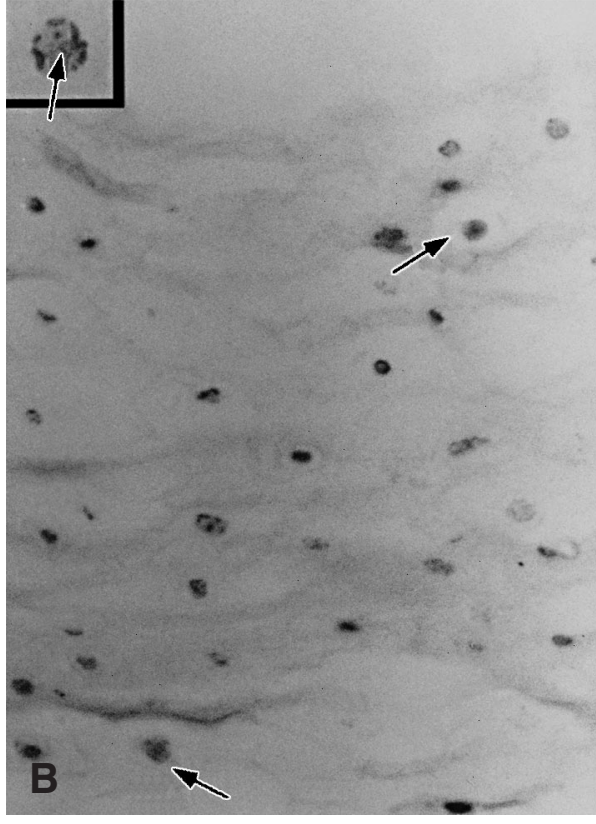

FIGURA 3 - Identificação do vírus Epstein-Barr na leucoplasia pilosa subclínica (caso 3). A: imuno-histoquímica vários ceratinócitos com inclusões tipo Cowdry A exibindo imunopositividade (seta) (400 X) -; detalhe Cowdry A com imunopositividade (seta) (1.000 X). B: hibridização in situ - células claras com núcleos positivos $(400 \mathrm{X})$-; detalhe - núcleo "em colar" e leve positividade central (1.000 X). 
DIAS, E. P.; SPYRIDES, K. S.; SILVA JUNIOR, A.; ROCHA, M. L.; FONSECA, E. C. da. Leucoplasia pilosa oral: aspectos histopatológicos da fase subclínica. Pesqui Odontol Bras, v. 15, n. 2, p. 104-111, abr./jun. 2001.

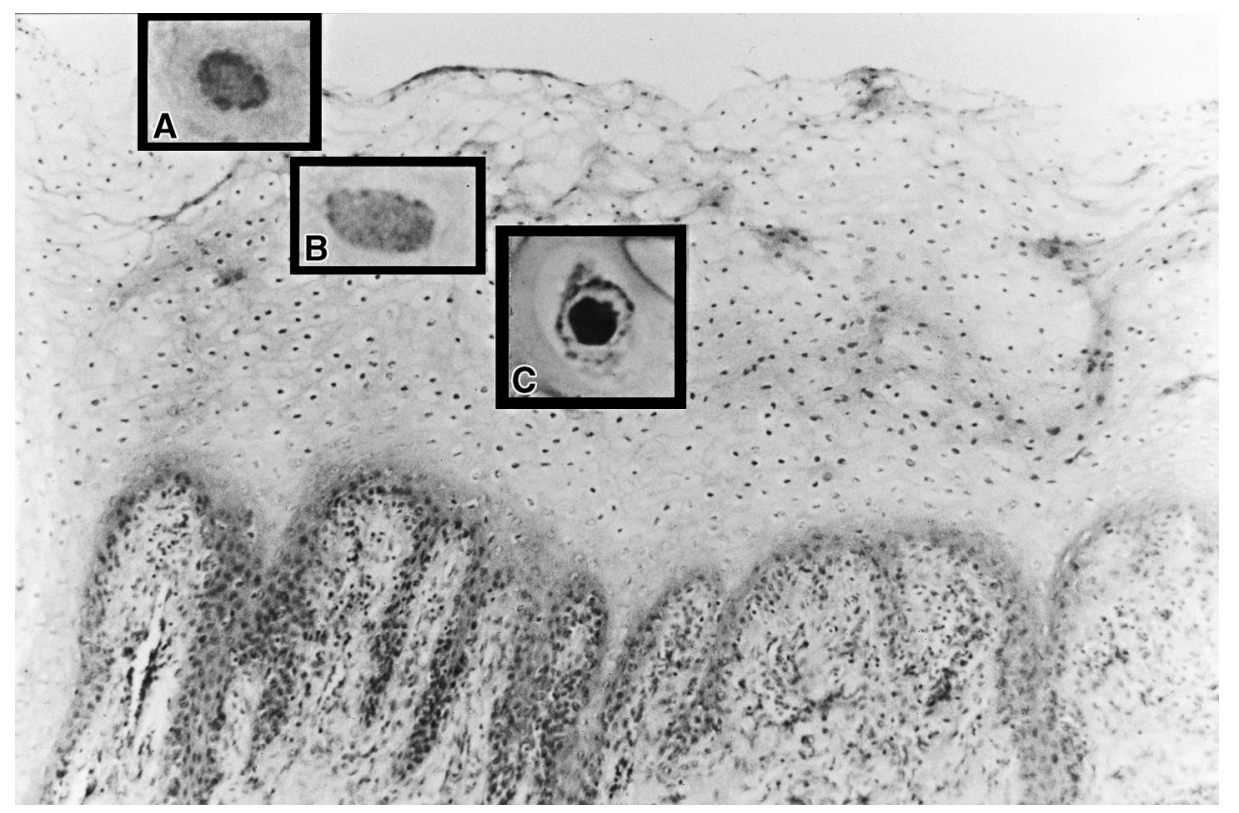

FIGURA 4 - Distribuição epitelial das alterações nucleares na leucoplasia pilosa oral subclínica (caso 6) (H.E., $100 \mathrm{X})$. Detalhes $(1.000 \mathrm{X})$ : núcleo "em colar" (A); núcleo em "vidro fosco" (B) e inclusão tipo Cowdry A (C).

Acreditamos que futuras investigações possam verificar o valor diagnóstico e prognóstico da detecção da LPO subclinica.

\section{CONCLUSÃO}

A leucoplasia pilosa oral apresenta aspectos histopatológicos característicos e suficientes para o diagnóstico, tanto em lesões clinicamente identificáveis quanto em lesões incipientes ou subclinicas. As principais diferenças histopatológicas entre as fases clínica e subclínica são quantitativas e expressam em maior ou menor intensidade o efeito citopático do EBV e a interferência na atividade proliferativa e diferenciação epitelial.

DIAS, E. P.; SPYRIDES, K. S.; SILVA JUNIOR, A.; ROCHA, M. L.; FONSECA, E. C. da. Oral hairy leukoplakia: histopathologic features of the subclinical stage. Pesqui Odontol Bras, v. 15, n. 2, p. 104-111, abr./jun. 2001.

Oral hairy leukoplakia (OHL) is one of the most common oral manifestations of AIDS, with diagnostic and prognostic value. OHL is associated to the Epstein-Barr virus and presents clinical and histological defined characteristics. There have already been reports about a subclinical stage of OHL, although they lacked histopathologic characterization. The present study had the aim to describe the histopathological characteristics of subclinical hairy leukoplakia, as well as to carry out a comparative analysis between clinical and subclinical OHL. For that, 11 cases were analyzed -5 biopsies from patients who presented with the lesion and 6 samples from the borders of tongues obtained in necropsies. The histopathological findings in subclinical OHL were: absence of parakeratosis and papillomatosis, mild acanthosis, ballooning cells and nuclear alterations. In situ hybridization and immunostaining were positive for EBV in the nuclear alterations identified in the histophatological analysis. Based on the identification of EBV in the nuclear alterations, it was possible to conclude that subclinical OHL, similarly to the clinical lesion, presents histopathological features that are specific and sufficient to establish the definitive diagnosis, regardless of the identification of the virus.

UNITERMS: Leukoplakia, hairy; Herpesvirus 4, human.

\section{REFERÊNCIAS BIBLIOGRÁFICAS}

1. ANDERSEN, L.; PHILIPSEN, H.; REICHART, P. Macro- and microanatomy of the lateral border of the tongue with special reference to oral hairy leukoplakia. J Oral Pathol Med, v. 19, p. 77-80, 1990.

2. AXÉLL, T.; BAERT, A. E.; BROCHERIOU, C. et al. An update of the classification and diagnostic criteria of oral lesions in HIV infection. J Oral Pathol Med, v. 2, n. 3, p. 97-100, 1991.

3. DIAS, E. P.; SILVA JÚNIOR, A.; FEIJO, E. C. et al. Diagnóstico citopatológico da leucoplasia pilosa. J Bras Patol, v. 35, n. 1, p. 23-28, 1999.

4. EISENBERG, E.; KRUTCHKOFF, D.; YAMASE, H. Incidental oral hairy leukoplakia in immunocompetent persons. Oral Surg, v. 74, n. 3, p. 332-333, 1992. 
DIAS, E. P.; SPYRIDES, K. S.; SILVA JUNIOR, A.; ROCHA, M. L.; FONSECA, E. C. da. Leucoplasia pilosa oral: aspectos histopatológicos da fase subclínica. Pesqui Odontol Bras, v. 15, n. 2, p. 104-111, abr./jun. 2001.

5. EPSTEIN, J. B.; FATAHZADEH, M.; MATISIC, J. et al. Exfoliative cytology and electron microscopy in the diagnosis of hairy leukoplakia. Oral Surg, v. 79, n. 5, p. 564-569, 1995.

6. EPSTEIN, J. B.; SHERLOCK, C. H.; GREENSPAN, J. S. Hairy leukoplakia-like lesions following bone-marrow transplantation. AIDS, v. 5, n. 1, p. 101-102, 1991.

7. EVERSOLE, L. R.; JACOBSEN, P.; STONE, C. E. et al. Oral condyloma planus (hairy leukoplakia) among homosexual men: a clinicopathologic study of thirty-six cases. Oral Surg, v. 61, n. 3, p. 249-255, 1986.

8. FELIX, D. H.; WATRET, K.; WRAY, D. et al. Hairy leukoplakia in an HIV-negative nonimmunosuppressed patient. Oral Surg, v. 74, n. 5, p. 563-566, 1992.

9. FOWLER, C.; REED, K.; BRANNON, R. Intranuclear inclusions correlate with the ultrastructural detection of herpes-type virions in oral hairy leukoplakia. Am J Surg Pathol, v. 13, n. 2, p. 114-119, 1989.

10. FRAGA-FERNÁNDEZ, J.; BENITO, C.; LIZALDEZ, E. B. et al. Oral hairy leukoplakia: a histopathologic study of 32 cases. Am J Dermatopathol, v. 12, n. 6, p. 571-578, 1990.

11. FRAGA-FERNÁNDEZ, J.; VICANDI-PLAZA, B. Diagnosis of hairy leukoplakia by exfoliative cytologic methods. Am J Clin Pathol, v. 97, n. 2, p. 262-266, 1992.

12. GREENSPAN, D.; GREENSPAN, J. S.; HEARST, N. G. et al. Relation of oral hairy leukoplakia to infection with the human immunodeficiency virus and the risk of developing AIDS. J Infect Dis, v. 155, n. 3, p. 475-581, 1987.

13. GREENSPAN, D.; GREENSPAN, J. S.; CONANT, M. et al. Oral hairy leukoplakia in male homosexuals: evidence of association with both papillomavirus and a herpes-group virus. Lancet, v. 2, p. 831-834, 1984.

14. GREENSPAN, D.; GREENSPAN, J. S. Significance of oral hairy leukoplakia. Oral Surg, v. 73, n. 2, p. 151-154, 1992.

15. GREENSPAN, J. S.; DE SOUZA, Y. G.; REGEZI, J. A. et al. Comparison of cytopathic changes in oral hairy leukoplakia with in situ hybridization for EBV-DNA. Oral Dis, v. 4, n. 2, p. 95-99, 1998.

16. ITIN, P.; RUFLI, T. Oral hairy leukoplakia. Int J Dermatol, v. 31, n. 5, p. 301-306, 1992.

17. KANAS, R. J.; BRAMS, A. M.; RECHER, L. et al. Oral hairy leukoplakia: a light microscopia and immunohistochemical study. Oral Surg, v. 66, n. 3, p. 332-340, 1988.

18. KANITAKIS, J.; EUVRARD, S.; LEFRANCOIS, N. et al. Oral hairy leukoplakia in a HIV-negative renal graft recipient. Br J Dermatol, v. 124, n. 5, p. 483-486, 1991.

19. KRATOCHVIL, F. J.; RIORDAN, P.; AUCLAIR, P. L. et al.
Diagnosis of hairy leukoplakia by ultrastructural examination of exfoliative cytologic specimens. Oral Surg, v. 70, n. 5, p. 613-618, 1990.

20. LASKARIS, G.; LASKARIS, M.; THEODORIDOU, M. Oral hairy leukoplakia in a child with AIDS. Oral Surg, v. 79, n. 5, p. 570-571, 1995.

21. LEGGOTT, P. J. Oral manifestations of HIV infection in children. Oral Surg, v. 73, n. 2, p. 187-192, 1992.

22. LEONARD, N.; McCREARY, C.; FLINT, S. F. et al. Autopsy findings in the tongues of 20 patients with AIDS. J Oral Pathol Med, v. 26, p. 244-247, 1997.

23. LÖNING, T.; HENKE, R.; REICHART, P. et al. In situ hybridization to detect Epstein-Barr virus DNA in oral tissues of HIV-infected patients. Virchows Arch, v. 412, p. 127-133, 1987.

24. MABRUK, M. J.; FLINT, S. R.; TONER, M. et al. Detection of Epstein-Barr virus DNA in tongue tissues from AIDS autopsies without clinical evidence of oral hairy leukoplakia. J Oral Pathol Med, v. 24, n. 3, p. 109-112, 1995.

25. MigLiORATI, C. A.; JONES, A. C.; BAUGHMAN, P. A. Use of exfoliative cytology in the diagnosis of oral hairy leukoplakia. Oral Surg, v. 76, n. 6, p. 704-710, 1993.

26. NÄHER, H.; GISSMAN, L.; DOEBERITZ, C. et al. Detection of Epstein-Barr virus DNA in tongue epithelium of human immunodeficiency virus-infected patients. J Invest Dermatol, v. 97, n. 3, p. 421-424, 1991.

27. RESNICK, L.; HERBST, J. S.; TRAUB-RAAB, N. Oral hairy leukoplakia. J Am Acad Dermatol, v. 22, n. 6, p. 1278-1282, 1990.

28. ROCHA, M. L.; DIAS, E. P.; FONSECA, E. C. Patologia da lingua: estudo prospectivo em 100 necropsias. Rev Pos-Grad, v. 6, n. 2, p. 139-46, 1999.

29. SANDVEJ, K.; KRENÁCS, L.; HAMILTON-DUTOIT, S. J. et al. Epstein-Barr virus latent and replicative gene expression in oral hairy leukoplakia. Histopathology, v. 20, n. 5, p. 387-395, 1992.

30. SCHMIDT-WESTHAUSEN, A.; GELDERBLOM, H.; HETZER, R. et al. Demonstration of Epstein-Barr virus in scrape material of lateral border of tongue in heart transplant patients by negative staining electron microscopy. J Oral Pathol Med, v. 20, p. 215-217, 1991.

31. SCIUBBA, J.; BRANDSMA, J.; SCHWARTZ, M. et al. Hairy leukoplakia: an AIDS-associated opportunistic infection. Oral Surg, v. 67, n. 4, p. 404-410, 1989.

32. SILVA JÚNIOR, A. Leucoplasia pilosa: aspectos clínicos, histopatológicos e citopatológicos. Niterói, 1996. 77 p. Dissertação (Mestrado) - Departamento de Patologia, Universidade Federal Fluminense.

Recebido para publicação em 09/02/00

Enviado para reformulação em $07 / 11 / 00$ Aceito para publicação em 21/03/01 